\title{
Effect of prior nonreward on subsequent incentive growth during brief acquisition
}

\author{
CHARLES I. BROOKS \\ King 's College, Wilkes-Barre, Pennsylvania 18702
}

\begin{abstract}
Four experiments compared runway extinction or hurdle-jumping from nonreward performance following brief (10 trials) continuous or partial reinforcement acquisition. Some of the partial groups received all nonrewarded trials prior to any rewards. The major findings were that (1) rats receiving all nonrewarded experiences prior to rewarded ones were more persistent during extinction than continuously rewarded subjects; (2) rats receiving nonrewarded placements prior to rewarded ones in one compartment of a two-compartment box, failed to learn a hurdle-jumping response to escape nonreward, whereas rats not receiving the initial nonrewards did learn the escape response; (3) increasing the number of rewarded placements following initial nonrewarded ones offset the effect noted in (2). The results, which are discussed in the context of a frustration analysis of the small-trials partial reinforcement effect, suggest that incentive growth over rewarded trials is retarded when the rewards have been preceded by nonrewards. The similarity of these results to those investigating the phenomenon of latent inhibition is apparent, and possible mechanisms responsible for the present results are suggested in current theoretical accounts of latent inhibition.
\end{abstract}

Spear, Hill, and O'Sullivan (1965) and Spear and Spitzner (1967) found that rats showed greater resistance to extinction than a consistently reinforced control group when they were given 24 nonrewarded trials followed by 24 rewarded trials. Mackintosh (1974) notes that these results are incompatible with any frustration accounts of the partial reinforcement effect (PRE), since the partially reinforced subjects received no reward before the nonreinforced trials, and thus could not have been frustrated on those trials. The frustration account of the PRE, of course (e.g., Amsel, 1958), requires that frustration stimuli be present during partially reinforced acquisition, and acquire habit strength for the instrumental response.

Capaldi and Waters (1970) obtained similar results, although their study involved a small number of acquisition trials. They found that rats given five reinforced trials in a runway preceded by five nonreinforced trials extinguished more slowly than rats given only five reinforced trials. Again, Mackintosh (1974) notes that these data are inconsistent with frustration theory which requires the development of an association of frustration stimuli with the goalapproach response. It should be noted, however, that one application of the frustration theory to the small trials PRE (SMPRE) (e.g., Brooks, 1969, 1971) avoids any assumptions about conditioned frustra-

The author thanks Joseph Franchina for his constructive and critical comments on the manuscript. Requests for reprints should be sent to Charles I. Brooks, Department of Psychology, King's College, Wilkes-Barre, Pennsylvania 18702. tion, and concentrates instead on levels of primary frustration. Specifically, this interpretation explains the SMPRE by assuming that, at the end of brief acquisition, continuously reinforced (CR) subjects have greater incentive $\left(r_{g}\right)$ than partially reinforced (PR) subjects. The $C R$ subjects thus experience greater primary frustration $\left(R_{f}\right)$ during extinction, and thus extinguish faster because of more intense goalavoidance responses elicited by the stimulus consequences of $R_{f}$. The key assumption of this analysis is that $r_{g}$ grows faster during CR than during PR acquisition. This assumption is made on two grounds: (1) In small-trial studies, CR subjects often receive more reward than PR subjects; and (2) the PR subjects receive nonrewarded trials, which are extinction trials for $r_{g}$.

The present studies were an attempt to see if Brooks' analysis of the SMPRE could be applied to Capaldi and Waters' (1970) data. Specifically the question was whether initial exposure to nonrewards retarded the growth of $r_{g}$ during subsequent rewards. If so, one could assume that rats receiving initial nonrewards would be less frustrated during extinction than rats not receiving the initial nonrewards, and thus should extinguish less slowly (the finding reported by Capaldi and Waters, 1970).

In the present studies,Experiment 1 was an attempt to replicate Capaldi and Waters' (1970) results while correcting some potential methodological problems. Experiments 2 and 3 used a hurdle-jumping measure (e.g., Brooks, 1969; Daly, 1969) to assess frustration levels in rats either receiving or not receiving initial 
nonrewards followed by consistent reward. Finally, Experiment 4 was an attempt to assess the compatibility of the preexposure effect over brief acquisition training with studies of latent inhibition (e.g., Dieter, 1977; Feldman, 1977).

\section{EXPERIMENT 1}

In Capaldi and Waters' (1970) study, either of two aspects of their procedure could have produced the result that subjects receiving initial nonrewards showed slower extinction than subjects not given the preexposure. (1) Their subjects received no exploration of the apparatus prior to acquisition. Thus, the initial nonrewarded trials in the $50 \%$ group could be viewed as exploration trials. This exploration could extinguish any fear of novel apparatus cues (McAllister, McAllister, \& Zellner, 1966), plus provide for the habituation of responses such as sniffing and grooming which could interfere with traversal of the alley. Some support for these possibilities is found in the fact that the subjects receiving the initial nonrewarded trials ran faster throughout acquisition than did the continuously reinforced group, which did not receive the nonrewarded trials. (2) The $50 \%$ group received 10 running trials, whereas the $100 \%$ group received only 5 trials. If one assumes that habit increases as a function of practice (e.g., Spence, 1956), then the extinction differences can be explained purely on the basis of differential habit strength of the running response. That is, the subjects receiving the initial 5 nonrewarded trials followed by the 5 rewarded ones should have a stronger running habit in extinction than the continuously reinforced group (five rewarded trials only), and thus extinguish more slowly.

Experiment 1 attempted to eliminate the above two possibilities by (1) giving all subjects exploration in the runway apparatus, and (2) equating habit strength of the running responses by giving the initial nonrewarded experiences for the $50 \%$ group in the form of direct placements into the goalbox, rather than running trials. Thus, in addition to having two groups similar to Capaldi and Waters' (1970) (i.e., a 50\% group receiving 5 nonrewarded running trials followed by 5 rewarded running trials, and a $100 \%$ group receiving 5 rewarded trials), two additional conditions were included. In one condition, the rats received 5 nonrewarded direct placements into the goalbox followed by 5 rewarded running trials. It is assumed that little or no habit for the running response builds up during direct placements (Theios \& Brelsford, 1964) and the use of the placements equates habit strength of the running response between this group and the one receiving only the 5 rewarded trials. In the final condition, rats received 5 rewarded placements followed by 5 rewarded running trials. This last condition was included because Capaldi and Waters also reported that there was no extinction difference between a group that received 5 rewarded acquisition trials and one that received 10 rewarded trials. The primary frustration $\left(R_{f}\right)$ analysis of the SMPRE would predict faster extinction in the latter group because more $r_{g}$ should develop during acquisition, and nonreward in extinction should thus yield greater $\mathbf{R}_{\mathrm{f}}$. One reason for the failure of Capaldi and Waters to find this difference could again involve the number of practice trials. That is, the greater habit strength in the group receiving 10 trials could offset the greater $R_{f}$ during extinction, Thus, the present experiment equated habit strength for the 5 - and 10-reward groups by having the initial 5 rewards in the 10-reward group delivered in the form of direct placements.

\section{Method}

Subjects. The subjects were 44 naive male albino rats from the laboratory colony, 90 to 122 days of age at the beginning of the experiment. Throughout the experiment, the rats were maintained on a deprivation schedule consisting of $11 \mathrm{~g}$ of Purina Lab Chow daily, with ad-lib water.

Apparatus. A straight, unpainted, wooden runway, $10 \mathrm{~cm}$ high and $10.2 \mathrm{~cm}$ wide, was divided into three sections by vertically sliding doors: a $29-\mathrm{cm}$ startbox, 141.3-cm alley, and $39.5-\mathrm{cm}$ goalbox. The startbox was covered with wire mesh, while the alley and goalbox were covered with sanded Plexiglas. Lafayette timers were connected to photorelay circuitry which activated photobeams placed $28.4,132.6$, and $167.3 \mathrm{~cm}$ from the startbox door. Running times, in $.01 \mathrm{sec}$, were measured between the first two beams, and goal times, in .01 sec, were measured between the last two beams. Rewards were placed in a copper-colored measuring spoon, which was centered on the end wall of the goalbox $4.5 \mathrm{~cm}$ from the floor. The spqon was bent up to conceal the presence or absence of food prior to the rat's breaking the final photobeam.

Design and Procedure. The rats were assigned to one of four runway-acquisition treatments $(n=11)$ : Group 5NT5RT received five nonrewarded running trials followed by five rewarded running trials; Group 5NP5RT received five nonrewarded direct placements into the goalbox of the runway, followed by five rewarded running trials; Group 5RP5RT received five rewarded direct placements into the goalbox, followed by five rewarded running trials; Group 5RT received five 30 -sec placements into a black, wooden box (to equate handling for all groups), followed by five rewarded running trials in the runway.

On Days 1-7, the rats were maintained on ad-lib food and water and handled daily. On Days 8-20, the subjects were habituated to the deprivation schedule. On Days 21 and 22, each rat explored the alley for $5 \mathrm{~min}$. All guillotine doors were open and all timing circuitry was activated. Thirty minutes after the exploration period ended, the rats received 30 -sec access to wet mash in the home cage, after which they received the daily ration of $11 \mathrm{~g}$.

Acquisition treatments occurred on Day 23. Placement procedures consisted of removing the rat from the black wooden retaining box and placing it in the goalbox with its head directly over the food cup (whether baited or unbaited). On rewarded placements, the rat received $30-\mathrm{sec}$ access to wet mash. On nonrewarded placements, the rat was confined in the unbaited goalbox for $30 \mathrm{sec}$. For a running trial, the rat was placed in the startbox with the startbox door open. When the subject broke the final photobeam in the goalbox, the goalbox door was closed. Reward and nonreward operations were the same as those for placements. After the fifth rewarded running trial, all subjects received an additional nonrewarded running trial, which served as the final acquisition trials.

On Day 24, the rats received 10 extinction trials. The procedures for a running trial were the same as those on the previous day, 
except that all trials were nonrewarded. In acquisition and extinction, if the rat failed to complete a section of the runway within $60 \mathrm{sec}$, it was placed directly in the goalbox and a $60-\mathrm{sec}$ latency was recorded for that section and for any subsequent one. The rats were always run in squads of four, one rat from each group. The order of running each day was randomized within each foursome. The ITIs varied from 4 to $7 \mathrm{~min}$.

\section{Results and Discussion}

The run and the goal measures provided the same statistical results, and only goal data are presented. Figure 1 presents mean reciprocals of goal time for each group as a function of acquisition trials. The curves for the three groups receiving only six trials are plotted beginning at point 6 . All four groups showed steady improvement in speeds over trials.

A Groups by Trials analysis of variance over points 6-11 provided significant effects of Groups $[F(3,40)=4.01, p<.025]$ and of Trials $[F(5,200)=$ $117.22, \mathrm{p}<.001]$. Subsequent Newman-Keuls tests were performed on the mean speeds averaged over Trials 6-11. Groups 5NT5RT (mean $=1.65$ ) and 5RP5RT (mean $=1.52$ ) did not differ, and were superior (ps $<.05$ ) to Groups 5NP5RT (mean $=$ 1.24 ) and 5RT (mean $=1.04)$.

The superiority of Group 5NT5R'T to Groups 5NP5RT and 5RT is consistent with the assumption that greater habit strength resulted from the extra practice trials in this group compared to the five-trial groups. Also, Group 5RP5RT showed elevated responding relative to 5NP5RT and 5RT. This difference suggests that the greater number of rewards received by Group 5RP5RT through the five placements and five running trials, produced greater $r_{g}$ than did the five-only rewards received by Group 5RT and Group 5NP5RT.

Figure 2 presents mean reciprocals of goal times for each group over extinction trials. There was a general increase in responding from Trial 1 to Trial 2.

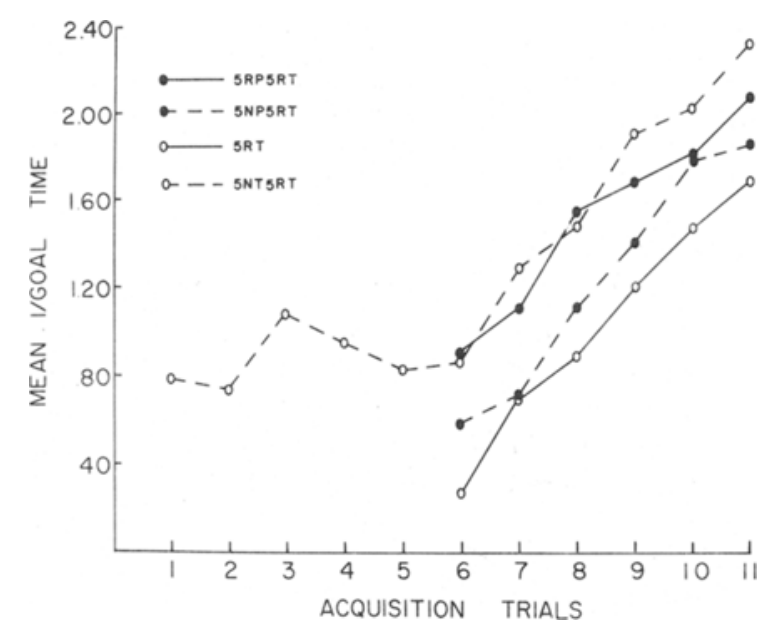

Figure 1. Goal speeds for each of the groups on each acquisition trial.

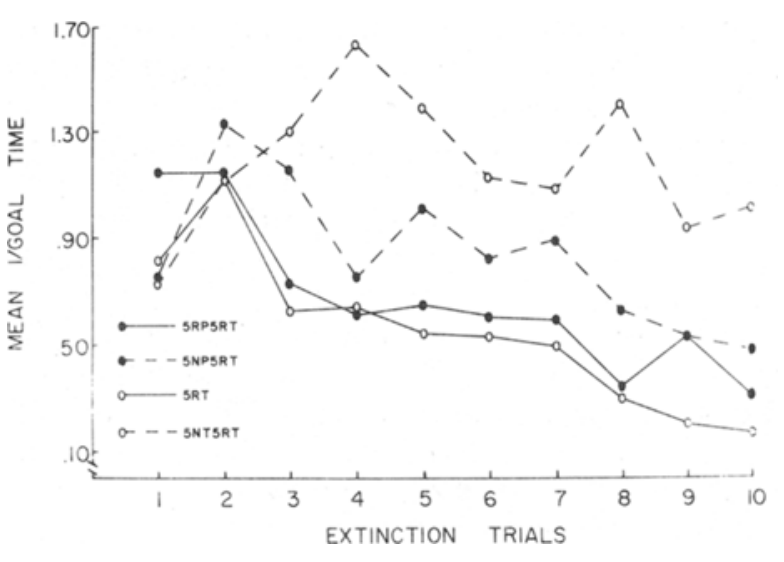

Figure 2. Goal speeds for each of the groups on each extinction trial.

This increase was also found by Capaldi and Waters (1970), and probably resulted from a warm-up decrement on Trial 1. The warm-up decrement between days is also supported by the fact that speeds on Trial 11 on Day 23 (see Figure 1) were higher than those on Trial 1 on Day 24 (Figure 2). Comparing the groups in Figure 2 over extinction trials, Group 5NT5RT showed a distinct superiority over the other groups and Group 5NP5RT generally performed at a level between that of Group 5NT5RT and the other two groups.

A Groups by Trials analysis of variance on the data in Figure 2 provided significant effects of Groups $[\mathrm{F}(3,40)=6.42, \mathrm{p}<.005]$, Trials $[\mathrm{F}(9,360)=9.94$, $\mathrm{p}<.001]$, and Groups by Trials $[\mathrm{F}(27,360)=2.78$, $\mathrm{p}<.001]$. Newman-Keuls tests were performed on the mean speeds averaged over all extinction trials. Group 5NT5RT $($ mean $=1.17)$ was superior $(\mathrm{ps}<$ .05 ) to Groups 5RP5RT (mean $=.66$ ) and 5RT(mean $=.54$ ). Groups 5NT5RT and 5NP5RT (mean $=.84$ ) did not differ, and nor did Group 5NP5RT differ significantly from Groups 5RP5RT and 5RT. Analysis by $t$ tests, however, did show a significant superiority $(\mathrm{p}<.05)$ of Group 5NP5RT over Groups 5RP5RT and 5RT.

It was expected that Group 5RP5RT would extinguish faster than Groups 5NP5RT and 5RT. Since all three groups received the same number of running trials, the groups are presumably equal with respect to habit strength. Since Group 5RP5RT received twice as many rewards as did Groups 5NP5RT and 5RT, however, Group 5RP5RT should have greater $r_{g}$ develop during acquisition. Thus, in extinction, $\mathbf{R}_{\mathrm{f}}$ should be greater for Group 5RP5RT, and this group should extinguish faster than Groups 5NP5RT and 5RT. In both the run and goal measures, however, only Group 5NP5RT showed a tendency toward superior responding in extinction compared to Group 5RP5RT. One possibility for the failure to obtain more convincingly the expected difference 
could be that acquisition and extinction were separated by $24 \mathrm{~h}$. As Brooks (1975) noted, frustration differences following orief acquisition training are generally more likely when acquisition and extinction trials are massed. This statement is based on the assumption that short-term frustration processes (i.e., $R_{f}$ ) are much stronger with massed training (e.g., Amsel, Wong, \& Traupmann, 1971). Since trial spacing appears to be an important variable in smalltrials phenomena, it might be maintained that frustration differences between Groups 5RP5RT, 5NP5RT, and 5RT would be maximal for only a short time after acquisition. The 24-h interval was used here to conform to Capaldi and Waters' (1970) procedure. The 4- to 7-min ITI of the present study may also have attenuated any $\mathbf{R}_{\mathrm{f}}$ differences (Amsel et al., 1971).

The finding of superior responding in extinction for Group 5NT5RT over Group 5RT replicated the finding reported by Capaldi and Waters (1970). This superiority appears to be due somewhat to greater habit strength in the 5NT5RT group, as evidenced by the superiority of this group over Group 5NP5RT. However, even with habit strength equated (Groups 5NP5RT and 5RT), and with possible differential fear of novel cues eliminated through extensive exploration, initial experience with nonreward still appeared to increase persistence of responding during extinction. Experiment 2 attempted to answer the question of whether or not this result could be incorporated into the primary frustration analysis of the small-trials PRE.

\section{EXPERIMENT 2}

Experiment 2 used a hurdle-jumping procedure to measure frustration following consistent rewards which were preceded or not preceded by a series of nonrewards. The speed with which an organism hurdle jumps (escapes) from nonreward is assumed to reflect the intensity of frustration elicited by nonreward (Daly, 1969, 1974). Frustration provides motivation, and frustration reduction provides reinforcement for the response. Therefore, if the difference between Groups 5RT and 5NP5RT in Experiment 1 was due to frustration differences, and if similar groups are compared on hurdle-jumping speed following either five rewarded placements or five rewarded placements preceded by five nonrewarded placements, then the former group should show faster hurdle-jumping performance. The same prediction would be made for another condition in Capaldi and Waters' (1970) study: two rewards, followed by five nonrewards, followed by three rewards. Since any $r_{g}$ developing on the first two trials could conceivably extinguish over the next five, this group should have less $r_{g}$ than a group receiving only five rewarded placements. Consequently, rats receiving such a partial schedule should be less frustrated by nonreward, and should thus escape from nonreward more slowly than rats receiving continuous reward.

Experiment 2 tested these predictions using three groups designated according to the placement schedule received prior to hurdle jumping: Groups $5 \mathrm{R}$, $5 N 5 R$, and $2 R 5 N 3 R$. The first two conditions are analogous to 5RT and 5NP5RT of Experiment 1, and Groups 5R and 2R5N3R are analogous to two conditions in the Capaldi and Waters (1970) study which found superior persistence in extinction in the partial group. Again, a frustration interpretation of that finding and the results of Experiment 1 lead to the prediction that Groups $5 R$ should show faster hurdle jumping than Group 2R5N3R or Group 5N5R.

\section{Method}

Subjects. Thirty-six naive male albino rats, 90 days of age, were obtained from the Holtzman Co., Madison, Wisconsin. Throughout the experiment, the rats were maintained on a deprivation schedule consisting of access to $11 \mathrm{~g}$ of Purina Lab Chow daily, with ad-lib water.

Apparatus. The apparatus, described fully by Brooks (1975, Experiment 2), consisted of a startbox and a goalbox separated by a guillotine door which rested on a hurdle. Raising the door activated a Lafayette timer, and interruption of a photobeam in the goalbox following a jump provided a measure of hurdlejumping latency in $.01 \mathrm{sec}$.

Procedure. Upon receipt from the supplier, the rats were placed in individual cages. On Days 1-7, the rats were maintained on ad-lib food and water and handled daily. On Days 8-20, the rats were habituated to the deprivation schedule and handled daily. On Days 21 and 22, the rats explored each section of the apparatus (one section at a time) for $3 \mathrm{~min}$. Following exploration, each rat received, in the home cage, access to wet mash for $30 \mathrm{sec}$ and then the daily ration. On Day 23 , placements were given. Group 5R received five reinforced placements into the startbox. Groups $2 R 5 N 3 R$ and $5 N 5 R$ received partially reinforced placement schedules as indicated. All R placements consisted of 30-sec access to wet mash in the startbox; $N$ placements consisted of 30 -sec confinement in the unbaited box. All ITIs were $20 \mathrm{sec}$, which the rats spent in an unpainted, wooden retaining box.

On Day 24 , each rat received 20 hurdle-jumping trials. The subject was placed in the unbaited startbox. After $5 \mathrm{sec}$, the guillotine door was raised as soon as the subject oriented fully to it. After a jump, the rat was left in the goalbox for $10 \mathrm{sec}$, and was removed to the retaining box for a $20-\mathrm{sec}$ ITI. If no hurdle jump occurred within $40 \mathrm{sec}$, the subject was removed to the retaining box and a 40 -sec latency was recorded. If three consecutive $40-\mathrm{sec}$ latencies occurred, training was terminated and 40 -sec latencies were recorded for all subsequent trials.

\section{Results and Discussion}

Figure 3 presents the reciprocals of hurdle-jumping latencies as a function of blocks of four trials. It is quite clear that only Group 5R showed acquisition of the jumping response.

A Groups by Trial Blocks analysis of variance on the data in Figure 3 provided significant effects of Groups $[F(2,33)=14.67, \mathrm{p}<.001]$, Trial Blocks $[\mathrm{F}(4,132)=5.36, \mathrm{p}<.001]$, and Groups by Trial Blocks $[F(8,132)=5.89, p<.001]$. A Newman-Keuls test performed on Trial Block 5 showed Group 5R (mean $=.80)$ superior $(\mathrm{ps}<.01)$ to both Groups 2R5N3R (mean $=.18$ ) and Group 5N5R (mean = $.13)$. 


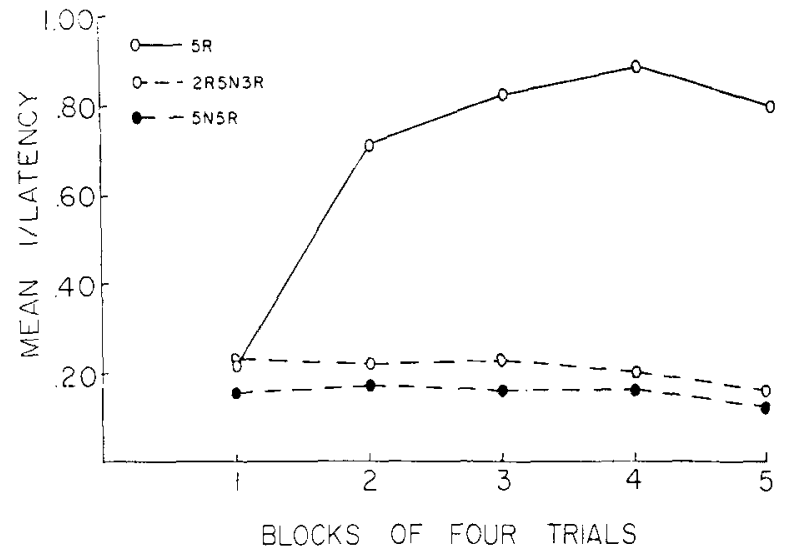

Figure 3. Speed of hurdle jumping from nonreward for each of the groups as a function of blocks of four hurdle-jumping trials.

The results of Experiment 2 support a frustration interpretation of the data in Experiment 1: A group receiving initial nonrewarded experiences prior to a small number of rewards enters extinction with a smaller amount of incentive $\left(r_{g}\right)$ than does a group not receiving the initial nonrewards. This reduced incentive led to less frustration in the empty goalbox in Group 5N5R than in Group 5R, and thus produced slower escape latencies from the empty goalbox. The data of Experiment 2 also replicate earlier small-trials studies (e.g., Brooks, 1975) showing slower escape from nonreward following partial reinforcement (Group 2R5N3R) than following continuous reinforcement (Group 5R) during acquisition.

\section{EXPERIMENT 3}

It should be noted that Experiment 2, which had a 24-h delay between placements and hurdle jumping (to conform to the procedure of Experiment 1), may not have provided an optimally sensitive measure of frustration resulting from the placement treatments. As noted earlier, the presence of any primary frustration following brief acquisition training is indicated more easily when extinction training is massed (Brooks, 1975). It is possible, therefore, that the 24-h interval between placements and hurdlejumping training weakened frustration elicited by nonreward during placement training. Although this possibility seems unlikely in view of the robust performance of Group 5R, Experiment 3 replicated Experiment 2, but gave placement and hurdlejumping training on the same day.

\section{Method}

Subjects. The rats were 30 naive male albino rats from the laboratory colony, 93-101 days of age. Throughout the experiment, the rats were maintained on a deprivation schedule consisting of access to $11 \mathrm{~g}$ of Purina Lab Chow daily, with ad-lib water.
Apparatus. The apparatus described in Experiment 2 was used. Procedure. On Days 1-20, the rats were habituated to the deprivation schedule and handled daily. On Days 21 and 22, each rat explored each section of the apparatus (one section at a time) for $3 \mathrm{~min}$. Following exploration, each subject received access to wet mash for $30 \mathrm{sec}$ in the home cage and then the daily ration. On Day 23, placements and hurdle-jumping training were given. Group $5 R$ received five reinforced placements into the startbox. Groups 2R5N3R and 5N5R received partially reinforced schedules as indicated. All $R$ placements consisted of 30-sec access to wet mash in the startbox, and $\mathbf{N}$ placements consisted of $30-\mathrm{sec}$ confinement in the unbaited box. All ITIs were $20 \mathrm{sec}$, which the rats spent in an unpainted wooden retaining box.

Twenty seconds after the last placement, each rat received 20 hurdle-jumping trials. The subject was placed in the unbaited startbox. After $5 \mathrm{sec}$, the guillotine door was raised as soon as the rat oriented fully to it. After a jump, the rat was left in the goalbox for $10 \mathrm{sec}$, and was removed to the retaining box for a $20-\mathrm{sec}$ ITI. If no hurdle jump occurred within $40 \mathrm{sec}$, the subject was removed to the retaining box and a $40-\mathrm{sec}$ latency was recorded. If three consecutive 40-sec latencies occurred, training was terminated and 40 -sec latencies were recorded for all subsequent trials.

\section{Results and Discussion}

Figure 4 presents the reciprocals of hurdle-jumping latencies as a function of blocks of four trials. The results conform to those of Experiment 2: Only Group 5R showed acquisition of the hurdle-jumping response.

A Groups by Trial Blocks analysis of variance on the data in Figure 4 provided significant effects of Trial Blocks $[\mathrm{F}(4,108)=7.70, \mathrm{p}<.001]$ and Groups by Trial Blocks $[F(8,132)=5.89, p<.001]$. Subsequent Newman-Keuls tests were performed on speeds on Trial Block 5. Group 5R (mean $=.92$ ) was superior (ps $<.01$ ) to both Groups 2R5N3R (mean $=.45$ ) and $5 \mathrm{~N} 5 \mathrm{R}$ (mean $=.34$ ). The latter two groups did not differ.

The data of Experiments 2 and 3 provide strong support for the interpretation that nonrewards in a partial reinforcement schedule weaken any $r_{g}$ that

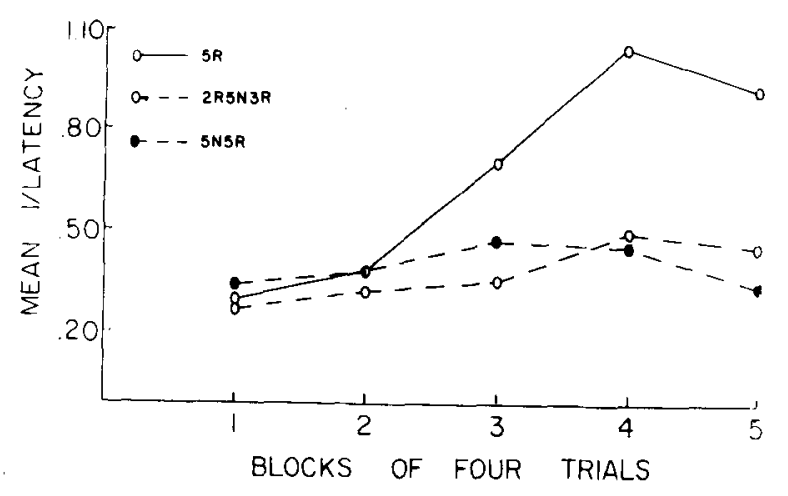

Figure 4. Speed of hurdle jumping from nonreward for each of the groups as a function of blocks of four hurdle-jumping trials. Hurdle-jumping training began 20 sec after the last placement. 
develops on rewarded trials. In a condition like 2R5N3R of Experiments 2 and 3, the assumed process by which nonreward reduces $r_{g}$ is fairly straightforward: any $r_{g}$ developing on the first two $R$ trials should undergo extinction over the next five $\mathrm{N}$ trials. In essence, then, one would say that frustration is being measured in subjects who have received either five (Group 5R) or three rewards (Group 2R5N3R). The situation may not be that simple, however, because Brooks (1971, Experiment 1) obtained acquisition of hurdle jumping after three rewards. Although that study involved a different apparatus and a different strain of rats, comparison with the present study suggests that three rewards preceded by nonreward produce less incentive than three rewards only. In any event, the superior hurdle-jumping performance of Group 5R over Group 2R5N3R may be explained by assuming some extinction of $r_{g}$ in the latter group on the $\mathbf{N}$ trials. During hurdle jumping, therefore, nonreward elicits less frustration in Group 2R5N3R than in Group 5R.

The superior hurdle jumping of Group 5R over Group 5N5R also suggests that Group 5R experienced greater frustration when nonrewarded. The $r_{g}$ analysis, however, does not seem as straightforward in this case. While a low level of $r_{g}$ and, hence, a low level of $\mathbf{R}_{\mathrm{f}}$ may account for the difference between Groups 5R and 2R5N3R, the occurrence of the $N$ trials prior to the receipt of reward makes an explanation of reduced $r_{g}$ due to extinction difficult to maintain. There should not be, after all, any $r_{g}$ present to undergo extinction during these initial N trials.

However, an argument for a lower level of $r_{g}$ in Group 5N5R compared to Group 5R may be made on grounds other than extinction of $r_{g}$ on the $\mathrm{N}$ trials. On the $\mathbf{N}$ trials prior to the receipt of reward, Group 5N5R received exposures to the cues of the goal situation without reward. These preexposures might have constituted the same type of stimulus preexposures which are known to promote latent inhibition (e.g., Lubow, Rifkin, \& Alek, 1976). If rewarded trials provide for the conditioning of $r_{g}$ to apparatus cues, and if preexposures to these cues prior to reward constitute procedures which are like those for latent inhibition, then prior exposures to apparatus cues on $\mathrm{N}$ trials before $\mathrm{R}$ trials might serve to attenuate the conditioning of $r_{g}$ to apparatus cues for Group 5N5R, but not for Group 5R. Thus, despite the equivalence of these groups in terms of reward experience (number of rewarded trials), they differed with respect to the level of $r_{g}$, and hence the level of $\mathbf{R}_{\mathrm{f}}$ in extinction.

\section{EXPERIMENT 4}

The data of Experiments 2 and 3 and the preceding latent inhibition analysis of the results raise the question of whether any experimental procedures can curtail the detrimental effect of prior nonreward on $r_{g}$ development over a small number of trials. Mackintosh (1974) notes that, following preexposure, the magnitude of latent inhibition is greatest on early conditioning trials. In the present studies, therefore, if $\mathbf{N}$ trials provide preexposure to goal-area cues and thus impede subsequent conditioning of $r_{g}$ to those cues on rewarded trials, then increasing the number of rewards following the initial nonrewards should reduce the latent inhibition effect. Experiment 4 tested this prediction by factorially combining 0 or 5 initial $\mathrm{N}$ placements with 5 or 10 subsequent rewarded placements in the hurdle-jumping situation. If increasing rewards following 5 initial nonrewards does weaken latent inhibition, then the group receiving 10 rewards (5N10R) should develop greater $r_{g}$ than the group receiving 5 rewards ( $5 N 5 R$ ). The 10 reward group should thus experience greater frustration when nonrewarded during hurdle-jumping, and hence should show better hurdle jumping than the 5-reward group.

The design of Experiment 4 also tests a straightforward prediction from the primary frustration analysis of the SMPRE: A consistently reinforced group given 10 rewards should experience greater frustration to nonreward than a consistently reinforced group given 5 rewards, and thus should hurdle jump faster to escape nonreward.

\section{Method}

Subjects. The subjects were 48 male albino rats, 90 days of age, obtained from the Holtzman Co., Madison, Wisconsin.

Apparatus. The hurdle-jumping apparatus of Experiments 2 and 3 was used.

Design and Procedure. Upon receipt from the supplier, the rats were placed in individual cages and randomly assigned to one of four groups $(n=12)$ according to placement number prior to hurdle jumping. Groups $5 R$ and $10 R$ received 5 and 10 rewarded placements, respectively. Groups $5 N 5 R$ and $5 N 10 R$ also received 5 and 10 rewarded placements, respectively, but these were preceded by 5 nonrewarded placements.

The rats were handled and maintained on ad-lib food and water for 1 week prior to the experiment. On Days $1-20$, the subjects were habituated to a deprivation schedule consisting of $11 \mathrm{~g}$ of Purina Lab Chow daily, with ad-lib water. On Days 21 and 22, each rat explored each section of the apparatus (one section at a time) for $3 \mathrm{~min}$. Following exploration, the rats received access to wet mash for $30 \mathrm{sec}$ in the home cage prior to receipt of the daily ration.

On Day 23, all placements and hurdle-jumping trials were given. All $\mathbf{R}$ placements consisted of $30-\mathrm{sec}$ access to wet mash in the startbox, and $\mathrm{N}$ placements consisted of 30 -sec confinement in the unbaited startbox. All ITIs were $20 \mathrm{sec}$, which the rats spent in an unpainted, wooden retaining box.

Twenty seconds after the last placement, each subject received 20 hurdle-jumping trials. The subject was placed in the unbaited startbox. After $5 \mathrm{sec}$, the guillotine door was raised when the subject oriented fully to it. After a jump, the subject was left in the goalbox for $10 \mathrm{sec}$, and then removed to the retaining box for a 20 -sec ITI. If no jump occurred within $40 \mathrm{sec}$, the subject was removed to the retaining box and a $40-\mathrm{sec}$ latency was recorded. If three consecutive 40 -sec latencies occurred, training was terminated and $40-\mathrm{sec}$ latencies were recorded for all subsequent trials. 


\section{Results and Discussion}

Figure 5 presents reciprocals of hurdle-jumping latencies over blocks of four trials. All the groups except 5N5R appeared to show acquisition of the response. Furthermore, in both $5 \mathrm{R}$ and both $10 \mathrm{R}$ conditions, the occurrence of the initial $\mathrm{N}$ experiences reduced hurdle-jumping performance, although the effect appears more pronounced in the $5 \mathrm{R}$ groups.

A mixed analysis of variance, with Nonrewarded ( $0 \mathrm{~N}$ vs. $5 \mathrm{~N}$ ) and Rewarded (5R vs. 10R) Placements as between factors and Trial Blocks as a within factor, was performed on the data in Figure 5. There were significant effects of Nonrewarded Placements $[F(1,44)=7.50, p<.01]$ and Rewarded Placements $[F(1,44)=10.41, p<.005]$, but no interaction of these factors $(p>.20)$. There were also a main effect on Trial Blocks $[\mathrm{F}(4,176)=27.89, \mathrm{p}<.001]$ and significant interactions of Trial Blocks by Nonrewarded Placements $[\mathrm{F}(4,176)=3.56, \mathrm{p}<.01]$ and Trial Blocks by Rewarded Placements $[\mathrm{F}(4,176)=4.44, \mathrm{p}<.005]$. The triple interaction was not significant $[\mathrm{F}(4,176)=$ 2.38, $p>.05]$. Thus, the initial nonrewards depressed hurdle jumping in both groups, and increasing the number of rewards increased hurdle-jumping performance.

Trial Blocks by Subjects analyses were performed for each group. Groups 5R, 10R, and 5N10R all showed significant acquisition of the hurdle response $[\mathrm{Fs}(4,44)=35.38,9.00,13.87$, respectively, $\mathrm{ps}<$ $.001]$, whereas Group 5N5R did not $(p>.20)$. Newman-Keuls tests were performed on hurdlejumping speeds on Trial Block 5. Groups 10R (mean $=1.02), 5 \mathrm{R}($ mean $=.85)$, and $5 \mathrm{~N} 10 \mathrm{R}$ (mean $=.80)$ did not differ, but all three were superior $(\mathrm{ps}<.01)$ to Group 5N5R (mean $=.19$ ).

The results of this experiment were consistent with those of Experiments 2 and 3 and predictions made on the basis of frustration. Group 5R showed greater hurdle jumping than did Group 5N5R, again showing that initial nonreward retards incentive growth

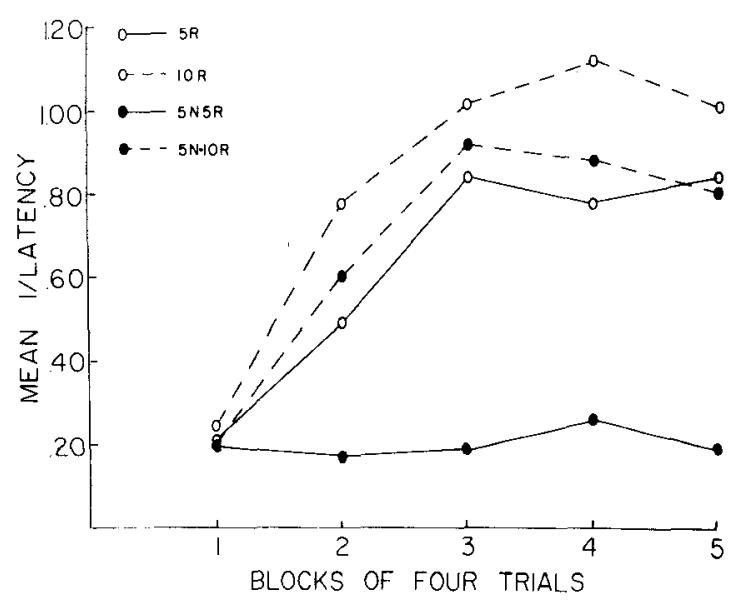

Figure 5. Speed of hurdle jumping from nonreward for each of the groups as a function of blocks of four hurdle-jumping trials. during acquisition and thus leads to weaker frustration elicited by nonreward in extinction. Since Group 5N10R showed significant acquisition of hurdle jumping, however, suggesting that this group was frustrated by nonreward, it may be concluded that the detrimental effect of the initial nonrewards can be attenuated by increasing the number of $\mathbf{R}$ trials following the initial $\mathbf{N}$ experiences. Finally, both 10R groups showed faster hurdle jumping than their respective $5 R$ groups. This result is consistent with the prediction that increasing rewards should increase incentive during acquisition, and lead to greater frustration during extinction.

\section{GENERAL DISCUSSION}

The present data are consistent with the results of previous studies by Brooks $(1969,1971,1975)$ in showing that greater frustration to nonreward occurs after a small number of continuously reinforced trials than after a small number of partially reinforced trials. In the present studies, rats given 5 continuous rewards consistently showed learning of a response to escape nonreward, whereas subjects given 5 rewards in a partial schedule did not show learning. The interpretation of this finding is that the frustration elicited by nonreward in the continuous subjects motivated the escape response, and frustration reduction provided reinforcement following the response. Furthermore, rats given 10 continuous rewards showed greater acquisition of the response to escape nonreward than rats given only 5 continuous rewards. Again, the interpretation of this difference is that nonreward elicits greater primary frustration in those rats receiving the larger number of rewards.

Additional data suggesting that frustration is a factor in small-trials studies have been provided by Collerain (1978) and Collerain and Ludvigson (1972). They present evidence that rats secrete an odor when nonrewarded, and that conspecifics will seek escape from that odor. This escape behavior suggests that the odor is aversive, and one may thus infer the presence of frustration. Of particular interest for an analysis of small-trials phenomena is the question of the rapidity with which this aversive odor develops. Collerain and Ludvigson (1972) found evidence for the presence of the odor after two to four rewarded experiences and Collerain (1978) found the odor after four reinforcements. These results suggest that rats find nonreward aversive after as few as four rewards, and the results are, therefore, quite compatible with a primary frustration analysis of the SMPRE.

The results of the present experiments also show that nonrewarded experience given prior to rewarded experience increases persistence of responding in extinction in brief acquisition situations (Experiment 1). Furthermore, it appears that this increased persistence results from a lowering of incentive dur- 
ing acquisition in groups receiving the initial nonrewards. This statement is based on the finding that subjects given the initial nonrewards followed by continuous reward do not show learning of hurdle jumping to escape nonreward. Subjects not receiving the initial nonrewards, however, do show such learning (Experiments 2 and 3). Thus, in the runway (Experiment 1), subjects which did not receive initial nonrewarded trials presumably experience greater primary frustration in extinction and thus extinguish faster than those subjects which did receive the initial nonrewards. Finally, increasing the number of rewards given after the initial nonrewards appears to overcome the effect of the preexposures (Experiment 4).

As noted earlier, the preexposure effect obtained in the present studies may be subsumed under the latent inhibition phenomenon, which refers to the deleterious effect of prior nonreinforced exposure to the conditioned stimulus on subsequent conditioning. In the present studies, the apparatus cues of the goal area represent the conditioned stimuli and $r_{g}$ represents the conditioned response. Nonreinforced exposure to these conditioned stimuli appears to retard their association with $r_{g}$ on subsequent reinforced trials.

Mackintosh $(1974$, p. 37) notes that there is some evidence that the magnitude of latent inhibition is greatest during the early stages of conditioning preexposure. The data of Experiment 4 are consistent with this observation, since the deleterious effect of the preexposure to nonreward was greater after 5 rewards (Group 5N5R) than after 10 rewards (Group $5 \mathrm{~N} 10 \mathrm{R})$.

A number of hypotheses have been developed to account for the latent inhibition phenomenon, any of which could handle the present data. Mackintosh (1973) has proposed a "learned-irrelevance" hypothesis which states that preexposed subjects learn to ignore the nonreinforced stimulus. Since the stimulus is uncorrelated with reinforcement, it is not attended to, and there is a reduction in the ability of that stimulus to enter into subsequent associations. In the present studies, then, it could be maintained that, during the initial nonrewarded trials, the animals learn that the goalbox cues do not meaningfully signal reinforcement. According to Wagner's (1976) analysis of latent inhibition, when a stimulus (CS) is repeatedly presented alone, an association is formed between the CS and the context in which it occurs. This association is represented in short-term memory, thereby reducing the likelihood of the original stimulus and a new stimulus being processed together on subsequent occasions. As a result, an association between the two stimuli should proceed slowly.

The latent inhibition analysis of the present data is probably not appropriate for those studies (e.g., Spear \& Spitzner, 1967) which investigated the effect on extinction responding of a large block of $\mathrm{N}$ trials given prior to a large block of $\mathrm{R}$ trials (24). While the initial $\mathrm{N}$ trials could interfere with the conditioning of $r_{g}$ during the $R$ trials, the results of Experiment 4 would lead to the expectation that $24 \mathrm{R}$ trials would overcome such interference. The inappropriateness of the latent inhibition analysis of $r_{g}$ differences in acquisition and, therefore, $R_{f}$ diferences in extinction for the large-trials situation is not surprising. An implicit assumption in applications of primary frustration to the small-trials PRE (Brooks, 1975) is that such motivational factors are of primary importance early in instrumental reward training. As training proceeds, there is an obvious need for associative mechanisms not necessarily based on motivational states (e.g., Capaldi, 1966).

\section{REFERENCES}

Amsel, A. The role of frustrative nonreward in noncontinuous reward situations. Psychological Bulletin, 1958, 55, 109-119.

Amsel, A., Wong, P. T., \& Traupmann, K. L. Short-term and long-term factors in extinction and durable persistence. Journal of Experimental Psychology, 1971, 90, 90-95.

Brooks, C. I. Frustration to nonreward following limited reward experience. Journal of Experimental Psychology, 1969, 81, 403-405.

Brooks, C. I. Frustration considerations of the small-trials partial reinforcement effect: Experience with nonreward and intertrial reinforcement. Journal of Experimental Psychology, 1971, 89, 362-371.

Brooks, C. I. Primary frustration differences following brief partial reinforcement acquisition under varying magnitudes of reward. Animal Learning \& Behavior, 1975, 3, 67-72.

CApaldi, E. J. Partial reinforcement: A hypothesis of sequential effects. Psychological Review, 1966, 73, 459-477.

Capaldi, E. J., \& Waters, R. W. Conditioning and nonconditioning interpretations of small-trials phenomena. Journal of Experimental Psychology, 1970, 84, 518.522.

Collerain, I. Frustration odor of rats receiving small numbers of prior rewarded running trials. Journal of Experimental Psychology: Animal Behavior Processes, 1978, 4, 120-130.

Collerain, I., \& Ludvigson, H. W. Aversion of conspecific odor or frustrative nonreward in rats. Psychonomic Science, 1972, 27, 54-56.

DALY, H. B. Learning of a hurdle-jump response to escape cues paired with reduced reward or frustrative nonreward. Journal of Experimental Psychology, 1969, 79, 146-157.

DALY, H. B. Reinforcing properties of escape from frustration aroused in various learning situations. In G. H. Bower (Ed.), The psychology of learning and motivation (Vol. 8). New York: Academic Press, 1974.

Dieter, S. E. Preexposure to situational cues and shock intensity in two-way avoidance learning. Animal Learning \& Behavior, 1977, 5, 403-406.

Feldman, M. A. The effects of preexposure to a warning or a safety signal on the acquisition of a two-way avoidance response in rats. Animal Learning \& Behavior, 1977, 5, 21-24.

Lubow, R. E., Rifkin, B., \& Alek, M. The context effect: The relationship between stimulus preexposure and environmental preexposure determines subsequent learning. Journal of Experimental Psychology: Animal Behavior Processes, 1976, 2, 38-47.

Mackintosh, N. J. Stimulus selection: Learning to ignore stimuli that predict no change in reinforcement. In R. A. Hinde \& J. S. Hinde (Eds.), Constraints on learning. London: Academic Press, 1973. 
Mackintosh, N. J. The psychology of animal learning. London: Academic Press, 1974.

McAllister, D. E., McAllister, W. R., \& Zellner, D. K. Preference for familiar stimuli in the rat. Psychological Reports, $1966,19,868-870$.

Spear, N. E., Hill, W. F., \& O'Sullivan, D. J. Acquisition and extinction after initial trials without reward. Journal of Experimental Psychology, 1965, 69, 25-29.

Spear, N. E., \& Spitzner, J. H. Effect of initial nonrewarded trials: Factors responsible for increased resistance to extinction. Journal of Experimental Psychology, 1967, 74, 525-537.

Spence, K. W. Behavior theory and conditioning. New Haven: Yale University Press, 1956.
Theios, J., \& Brelsford, J. Overlearning-extinction effect as an incentive phenomenon. Journal of Experimental Psychology, 1964, 67, 463-467.

Wagner, A. R. Priming in STM: An information processing mechanism for self-generated or retrieval-generated depression in performance. In T. J. Tighe \& R. N. Leaton (Eds.), Habituation: Perspectives from child development, animal behavior and neurophysiology. Hillsdale, N.J: Erlbaum, 1976.

(Received for publication January 16, 1979; revision accepted August 1,1979.) 